\title{
Dominant-negative Effect of a Mutant Cardiac Troponin T on Cardiac Structure and Function in Transgenic Mice
}

\author{
Leslie Oberst, Guiling Zhao, Jong T. Park, Ramon Brugada, Lloyd H. Michael," Mark L. Entman, ${ }^{\star}$ Robert Roberts, \\ and Ali J. Marian \\ Section of Cardiology and *Section of Cardiovascular Sciences, Department of Medicine, Baylor College of Medicine, Houston, \\ Texas 77030
}

\begin{abstract}
Hypertrophic cardiomyopathy (HCM) is a disease of sarcomeric proteins. The mechanism by which mutant sarcomeric proteins cause HCM is unknown. The leading hypothesis proposes that mutant sarcomeric proteins exert a dominant-negative effect on myocyte structure and function. To test this, we produced transgenic mice expressing low levels of normal or mutant human cardiac troponin $\mathrm{T}$ (cTnT).

We constructed normal (cTnT-Arg ${ }^{92}$ ) and mutant (cTnT$\mathrm{Gln}^{92}$ ) transgenes, driven by a murine cTnT promoter, and produced three normal and five mutant transgenic lines, which were identified by PCR and Southern blotting. Expression levels of the transgene proteins, detected using a specific antibody, ranged from 1 to $10 \%$ of the total cTnT pool. M-mode and Doppler echocardiography showed normal left ventricular dimensions and systolic function, but diastolic dysfunction in the mutant mice evidenced by a $50 \%$ reduction in the $\mathrm{E} / \mathrm{A}$ ratio of mitral inflow velocities. Histological examination showed cardiac myocyte disarray in the mutant mice, which amounted to $1-15 \%$ of the total myocardium, and a twofold increase in the myocardial interstitial collagen content.

Thus, the mutant cTnT-Gln ${ }^{92}$, responsible for human HCM, exerted a dominant-negative effect on cardiac structure and function leading to disarray, increased collagen synthesis, and diastolic dysfunction in transgenic mice. $(J$. Clin. Invest. 1998. 102:1498-1505.) Key words: gene expression • mutation • myocyte disarray • echocardiography
\end{abstract}

\section{Introduction}

Familial hypertrophic cardiomyopathy $(\mathrm{HCM})^{1}$ is an autosomal dominant disease characterized by cardiac myocyte disarray and hypertrophy in the absence of an increased external load (1). While cardiac hypertrophy is similar to that observed with an increased load and other forms of injury, myocyte disarray, in contrast, is essentially a unique pathological hallmark

Address correspondence to A.J. Marian, M.D., Assistant Professor of Medicine, Section of Cardiology, One Baylor Plaza, 543E, Houston, TX 77030. Phone: 713-798-7454; FAX: 713-798-3147; E-mail: amarian @bcm.tmc.edu

Received for publication 22 May 1998 and accepted in revised form 21 August 1998.

J. Clin. Invest.

(C) The American Society for Clinical Investigation, Inc. 0021-9738/98/10/1498/08 \$2.00

Volume 102, Number 8, October 1998, 1498-1505

http://www.jci.org of HCM (2). Multiple genes responsible for HCM that encode for sarcomeric proteins have been identified, namely, the $\beta$-myosin heavy chain ( $\beta$-MyHC), cardiac troponin T (cTnT), cardiac troponin I, myosin binding protein-C (MyBP-C), $\alpha$-tropomyosin, and the essential and regulatory myosin light chains (3-8). The diverse nature of the responsible genes and their mutations accounts, in part, for the variable phenotypic expression of HCM, in particular the magnitude of cardiac hypertrophy and the risk of sudden cardiac death (9-12). In general, cardiac hypertrophy is a common phenotype in patients with the $\beta$-MyHC mutations, however, the extent of hypertrophy is determined in part by the specific mutation (9-13). In contrast, mutations in the cTnT and MyBP-C genes are associated with minimal or no hypertrophy $(9,10,14)$.

While mutations in the sarcomeric proteins have been shown to be the etiology of HCM, the mechanism responsible for HCM phenotypes remains unknown. Experimental studies, in conjunction with clinical observations, suggest that the hypertrophy is compensatory to impaired function of the mutant sarcomeric proteins (15-22). In vitro motility studies of isolated mutant $\mathrm{MyHC}$ proteins and slow muscle fibers from patients with the $\beta$-MyHC mutations show impaired contractility $(16,17)$. Similarly, expression of the mutant cTnT or $\beta$-MyHC proteins in cardiac myocytes or cultured myotubes is associated with an impaired cell shortening followed by sarcomere disarray (18-20). Cardiac myocyte disarray also has been induced through expression of a mutant $\alpha-\mathrm{MyHC}$ as a transgene in the mouse (21) and also after insertion by homologous recombination (22). The results of these experiments have led to a proposed mechanism for HCM which suggests that mutant sarcomeric proteins, after incorporation into myofibrils, exerts a dominant-negative effect on cardiac myocyte structure and function. To further test this hypothesis, we studied the impact of low levels of expression of a mutant troponin T gene, known to cause HCM in humans, on cardiac structure and function in transgenic mice. Using specific probes and antibodies that differentiate between the human and murine cTnT mRNAs and proteins, we quantified relative expression levels of the mutant cTnT mRNA and protein. Cardiac dimensions, FS, and diastolic function were assessed by M-mode and Doppler echocardiography and the extent of cardiac myocyte disarray was quantified by digital planimetry of myocardial sections.

1. Abbreviations used in this paper: $\mathrm{cTnT}$, cardiac troponin $\mathrm{T}$; EDD, end-diastolic diameter; ESD, end-systolic diameter; FS, fractional shortening; GAPDH, glyceraldehyde-3-phosphate dehydrogenase; $\mathrm{HCM}$, hypertrophic cardiomyopathy; MyBP-C, myosin binding protein-C; MyHC, myosin heavy chain; PWT, posterior wall thickness; ST, septal thickness. 


\section{Methods}

The institutional Recombinant DNA, Animal Research, and Biohazard Committees approved the protocols used in this project.

Transgenes. A full-length human cTnT cDNA was isolated from a normal human heart cDNA library (Stratagene, La Jolla, CA) and sequenced (19). The $\mathrm{G} \rightarrow \mathrm{A}$ substitution that results in $\mathrm{Arg}^{92} \mathrm{Gln} \mathrm{mu}-$ tation in the protein was induced by oligonucleotide-mediated sitedirected mutagenesis (23). The normal and mutant cTnT cDNAs were subcloned into EcoRV and NotI sites in a pcDNA3 vector (Invitrogen, Carlsbad, CA). A previously characterized -497 bp fragment of murine cTnT promoter, provided kindly by Dr. Jim Lin at the University of Iowa (24), was placed 5' to the human cTnT cDNA clones into HindIII and BamHI sites.

Generation and identification of transgenic mice. The entire transgene expression cassettes, comprised of murine cTnT promoter and human cTnT-Arg ${ }^{92}$ or cTnT-Gln ${ }^{92}$ cDNAs, were excised from the corresponding clones as HindIII-NotI fragments. The HindIII-NotI fragments were gel-purified, dissolved in Tris-HCl-EDTA at a final concentration of $100 \eta \mathrm{g} / \mu \mathrm{l}$, and were injected into the pronucleus of 80 (40 for each transgene) fertilized zygotes harvested from ICR/ B6C3F1 mice. Dr. F. DeMayo using the conventional methods (25) generated the transgenic mice in the Baylor College of Medicine Transgenic Mice Facility.

Transgenic mice were identified by PCR using transgene-specific oligonucleotide primers. In brief, genomic DNA was extracted from tail biopsies using proteinase- $\mathrm{K}$ and a set of oligonucleotide primers (forward 5'gatgacatccaccagaagcgcatg3' and reverse 5'ttactggtgtggagtgggtgtg $3^{\prime}$ ) was designed to amplify an 818-bp fragment of the cTnT transgene. A second set of primers (forward 5'agaaacggaatgttgtggagt $3^{\prime}$ and reverse $5^{\prime}$ gatgtgctccaggctaaagtt $3^{\prime}$ ) was also used in the PCR reaction to amplify a 500-bp fragment of the mouse $\beta$-casein gene as an internal control. PCR reaction contained $1.5 \mathrm{mM}$ of $\mathrm{MgCl}_{2}$ and the annealing temperature was $60^{\circ} \mathrm{C}$.

Southern blotting was performed as described previously (26). In brief, $10-\mu \mathrm{g}$ aliquots of DNA were digested overnight with $40 \mathrm{U}$ of HindIII and NotI, to release the entire transgene. The digested products were subjected to electrophoresis in $1 \%$ agarose gel and transferred to a nylon membrane. A 711-bp fragment of murine cTnT promoter which hybridizes to transgene as well as endogenous cTnT promoter was radiolabeled to a specific activity of $>10^{9} \mathrm{cpm} / \mu \mathrm{g}$ with $\left.{ }^{32} \mathrm{P}\right] \mathrm{dCTP}$ (Amersham Corp., Arlington Heights, IL) by the random primer procedure of Feinberg and Vogelstein (27). The radiolabeled probe was hybridized to membranes in the presence of Denhardt's reagent $(0.1 \%$ Ficoll, $0.1 \%$ polyvinylpyrrolidone, $0.1 \%$ BSA, and 100 $\mu \mathrm{g} / \mathrm{ml}$ of denatured fragmented salmon sperm DNA) in hybridization solution ( $6 \times \mathrm{SSC}, 0.5 \% \mathrm{SDS})$ for $18 \mathrm{~h}$. The membranes were then washed and exposed to an x-ray film (XAR-5; Eastman Kodak Co., Rochester, NY) in the presence of intensifying screens for $24 \mathrm{~h}$.

Northern blotting. Total RNA was extracted from the myocardium by guanidinium isothiocyanate and quantified by measuring its absorption at $260 \mathrm{~nm}$ (28). A 10- $\mu$ g aliquot of total RNA was loaded onto a formaldehyde-agarose gel, subjected to electrophoresis, and transferred to a nylon membrane (Zeta Probes; Bio-Rad Laboratories, Cambridge, MA). Sequences of human and mouse cTnT mRNAs were compared $(29,30)$, and transgene-specific, mouse-specific, and pan-specific cTnT probes were designed. The transgene-specific and pan-specific probes were 160- and 950-bp-long and were excised from the $3^{\prime}$ and $5^{\prime}$ region of human cTnT cDNA, respectively. The mousespecific probe was 150-bp-long and was amplified by PCR (primers were: forward $5^{\prime}$ ctgtgccccetgcttgtgtccttg $3^{\prime}$, reverse $5^{\prime}$ ggcatagtgcgggcataggggt $3^{\prime}$ ) from the $3^{\prime}$ end of mouse cTnT gene (30). Radiolabeling of the probes, hybridization, washing, and autoradiography were performed as described above. Membranes were initially hybridized to the transgene-specific probe, then to the endogenous cTnT probe, a pan-specific probe, and finally to the glyceraldehyde-3-phosphate dehydrogenase (GAPDH) probe. After each hybridization, the probe was stripped off the membrane and autoradiography was repeated to confirm complete disposal of the probe from the membrane. Densities of the bands corresponding to transgene, endogenous, and total cTnT mRNA were measured using an image digitizer/analyzer (Alpha Imager 2000, version 3.0; Alpha Inotech Corp., San Leandro, CA) and corrected for that of GAPDH mRNA band.

Immunoblotting. Mice were killed, and hearts were explanted and weighed after excision of the great vessels. Cross-sectional slices parallel to the atrioventricular groove were cut at $2 \mathrm{~mm}$ thickness and washed three times with ice-cold relaxing (RS) buffer $(80 \mathrm{mM} \mathrm{KCl}$, $10 \mathrm{mM} \mathrm{MgCl}$, $1 \mathrm{mM}$ EDTA, $5 \mathrm{mM}$ ATP, $6.6 \mathrm{mM}$ potassium phosphate, $\mathrm{pH} 6.35$, and protease inhibitors aprotinin $[1 \mu \mathrm{g} / \mathrm{ml}]$, pepstatin A [1 $\mu \mathrm{g} / \mathrm{ml}]$, and PMSF [100 $\mu \mathrm{g} / \mathrm{ml}]$ ). Sections were homogenized in 1 $\mathrm{ml}$ of RS buffer to which $0.5 \mathrm{M}$ sucrose, $0.5 \%$ Triton $\mathrm{X}-100$, and 1 $\mathrm{mM}$ DTT were added in a glass homogenizer for 24 times while taking care not to produce bubbles or to press the sections against the bottom of the apparatus (31). Then sections were pelleted in $15-\mathrm{ml}$ conical polycarbonate tubes at 3,000 rpm for $5 \mathrm{~min}$. Homogenization and pelleting were repeated three times, and the final pellet was suspended in a lysis buffer ( $2 \%$ Triton X-100, Tris- $\mathrm{HCl} 50 \mathrm{mM}, 5 \mathrm{mM}$ bromomercaptoethanol) in a glass homogenizer by 600 strokes performed in $1 \mathrm{~h}$. The homogenates were then centrifuged at $4^{\circ} \mathrm{C}$ at 3,500 rpm in a benchtop centrifuge for $15 \mathrm{~min}$ and supernatant was carefully removed. Concentration of the total protein, in each extract, was determined by a spectrophotometer using a protein assay kit (BioRad, Hercules, CA). A $20-\mu \mathrm{g}$ aliquot of total protein extract was loaded onto each well in a $12 \%$ nondenaturing SDS-polyacrylamide gel and was subjected to electrophoresis. The separated proteins were transferred to PVDF (Bio-Rad) membranes. After incubation with a blocking buffer which was comprised of $0.1 \%$ Tween $20,5 \%$ goat serum in $1 \times$ PBS, membranes were first treated with transgene-specific monoclonal anti-human troponin T antibody 2D10 (Research Diagnostic Inc., Flanders, NJ) at 1:1,000 dilution for $60 \mathrm{~min}$ at room temperature. Membranes were then exposed to 1:10,000 dilution of goat anti-mouse alkaline phosphatase conjugate for $60 \mathrm{~min}$ and the signals were detected by chemiluminescence per recommendation of the manufacturer (CLONTECH, Palo Alto, CA).

To detect expression levels of the total cTnT proteins (transgene plus endogenous), antibodies were stripped off the membranes in a buffer that contained $100 \mathrm{mM}$ BME, $2 \%$ SDS, $62.5 \mathrm{mM}$ Tris- $\mathrm{HCl}$, and $0.1 \%$ Tween 20 at $65^{\circ} \mathrm{C}$ for $2 \mathrm{~h}$. The membranes were washed in $1 \times$ PBS, and incubated with a pan-specific monoclonal anti-troponin $\mathrm{T}$ antibody clone JLT-12 (Oncogene, Cambridge, MA). This antibody cross-reacts with transgene and endogenous cTnT proteins equally. The densities of the bands corresponding to cTnT proteins were measured using an image digitizer/analyzer (Alpha Imager 2000, version 3.0; Alpha Inotech Corp.).

M-mode and Doppler echocardiography. M-mode and Doppler echocardiography were performed in the DeBakey Heart Center Core Animal Laboratory by a technician who was blinded to mouse genotype (32-35). In brief, mice were anesthetized lightly by intraperitoneal injection of $10 \mu \mathrm{g} / \mathrm{ml}$ dilution of pentobarbital sodium at the dose of $10 \mu \mathrm{l} / \mathrm{g}$. Body furs on the upper sternal and subxiphoid areas were shaved and moistened for a better acoustic coupling. Limbs were attached to copper electrodes for electrocardiographic monitoring and timing of cardiac cycles. M-mode echocardiographs of the left ventricle were recorded at the tip of mitral valve apparatus using a 5-7.5-MHz transducer. Interventricular septal thickness (ST), posterior wall thickness (PWT), and left ventricular end-systolic (ESD) and end-diastolic diameters (EDD) were measured and percent fractional shortening (FS) was calculated as (EDD - ESD)/EDD. Mitral inflow and aortic outflow velocities were obtained from the subxiphoid area using a $10-\mathrm{MHz}$ pulsed Doppler probe with depth set of 4-7 mm. Aortic outflow tract velocities were also obtained from the right sternal border at Doppler range gate depth of 2-4-mm-deep and the highest velocities were used for measurements. Early (E) and atrial (A) velocities across mitral valve inflow as well as the peak systolic velocity of aortic outflow were recorded for several cycles per set and in two sets for each animal. To reduce the influence of poten- 
tial confounding factors on Doppler indices, the mean values for three measurements were used. To control for the influence of heart rate variability, Doppler indices were measured from tracings that had equal cycle lengths. To minimize the influence of preload on Doppler indices, only cardiac cycles that had equal preceding cycle lengths were analyzed. A single individual without knowledge of mouse genotype interpreted the echocardiographic studies. The intraobserver variability of peak aortic outflow, E and A velocities was measured for 20 mice on two different days without knowledge of mouse genotype and in a random sequence.

Histological studies. 3-mo-old mice (six per line, and mostly male) were killed, and hearts were explanted and weighed after excision of the great vessels. Myocardium was cross-sectioned into 2-mmthick sections parallel to the atrioventricular groove. Section were fixed in formalin and embedded in paraffin. Transverse sections at midventricular level near the tip of the papillary muscles were cut into 5- $\mu \mathrm{m}$-thin sections, stained with hematoxylin and eosin or picrosirius red, and examined under light microscopy by a pathologist who was blinded to mouse genotype. Regions of the myocardium at the junction of the two ventricles with interventricular septum were excluded for analysis for cardiac myocyte disarray. The percentage of myocardial cross-sectional areas that exhibited myocyte disarray was quantified by digital planimetry using a computer image analysis program (Image Tool 2.0; UTHSCSA, San Antonio, TX) in 10 sections per mice. The amount of interstitial collagen in the myocardium was determined by a previously described method, which is based on selective binding of sirius red F3BA with collagen (36). The sirius red F3BA dye was eluted from 30 myocardial sections in each group by adding $0.1 \mathrm{~N} \mathrm{NaOH}$ in absolute methanol $(1: 1, \mathrm{vol} / \mathrm{vol})$, and the absorbency of the eluted color at $540 \mathrm{~nm}$ was determined using a spectrophotometer (36).

\section{Results}

Generation and identification of the transgenic mice. The size of the cloned cTnT cDNA was $1.11 \mathrm{~kb}$. It coded for a 288 -amino acid cTnT protein with an expected molecular size of $35 \mathrm{kD}$. The sequence of the cTnT protein was completely identical to that of adult cTnT protein published by Townsend et al. (29). The successful induction of a $\mathrm{G} \rightarrow \mathrm{A}$ nucleotide substitution ( $A \operatorname{rg}^{92}$ Gln mutation) in the cTnT cDNA was confirmed by sequencing. The sequences of cTnT-Arg ${ }^{92}$ and cTnT-Gln ${ }^{92}$ transgenes were identical except for the substitution of glutamine for arginine at position 92 of the cTnT protein.

Eight founder mice, three harboring the cTnT-Arg ${ }^{92}$ and five harboring the cTnT-Gln ${ }^{92}$ transgenes, were identified by PCR and Southern blotting, the latter showed the presence of the 1.6-kb transgene and the $\sim 6-\mathrm{kb}$ endogenous fragments. A representative result of PCR screening is shown in Fig. 1. The presence of the 818-bp product, amplified from transgene using transgene-specific primers, identified the transgenic mice.
Table I. Morphological and Echocardiographic Indices in Transgenic Mice

\begin{tabular}{lccc}
\hline & NLM & cTnT-Arg $^{92}$ & cTnT-Gln \\
\hline & $n=6$ & $n=9$ & $n=9$ \\
Body wt (g) & $40.4 \pm 6$ & $36.9 \pm 5.3$ & $43.6 \pm 6.6$ \\
Heart wt (mg) & $261.1 \pm 23.7$ & $236.4 \pm 62.8$ & $241 \pm 51.1$ \\
Heart wt/body wt & $6.6 \pm 1.1$ & $6.4 \pm 1.6$ & $5.6 \pm 1.0$ \\
HR (bpm) & $346 \pm 32$ & $317 \pm 46$ & $339 \pm 41$ \\
ST (mm) & $0.8 \pm 0.1$ & $0.9 \pm 0.1$ & $0.9 \pm 0.1$ \\
PWT (mm) & $0.8 \pm 0.1$ & $0.8 \pm 0.1$ & $0.8 \pm 0.1$ \\
LVEDD (mm) & $4.0 \pm 0.6$ & $4.1 \pm 0.6$ & $3.5 \pm 0.7$ \\
LVESD (mm) & $2.2 \pm 0.4$ & $2.3 \pm 0.5$ & $2.1 \pm 0.5$ \\
FS $(\%)$ & $45 \pm 7$ & $41 \pm 5$ & $40 \pm 7$ \\
Peak Ao Vel. $(\mathrm{cm} / \mathrm{s})$ & $82 \pm 5$ & $98 \pm 12$ & $84 \pm 8$ \\
Peak E Vel. $(\mathrm{cm} / \mathrm{s})$ & $80 \pm 7$ & $78 \pm 9$ & $67 \pm 8$ \\
Peak A Vel. $(\mathrm{cm} / \mathrm{s})$ & $15 \pm 4$ & $14 \pm 6$ & $30 \pm 7 *$ \\
E/A ratio & $5.3 \pm 0.9$ & $5.6 \pm 0.8$ & $2.2 \pm 0.7 *$ \\
& & & \\
\hline
\end{tabular}

HR, Heart rate; Peak Ao Vel., peak aortic velocity; Peak E Vel., peak early velocity; Peak $A$ Vel., peak atrial velocity. $* P<0.0001$ between the three groups (ANOVA) and $P<0.001$ between cTnT-Arg ${ }^{92}$ and cTnT-Gln ${ }^{92}$ (Student's $t$ test).

Gross morphology. Gross cardiac morphology, heart weight, and heart/body weight ratios were not significantly different among the cTnT-Arg ${ }^{92}$ and cTnT-Gln ${ }^{92}$ transgenic mice and their respective normal littermates (Table I).

Northern blot analysis. Expression of the cTnT-Arg ${ }^{92}$ and cTnT-Gln ${ }^{92}$ transgenes into mRNA was confirmed and quantified by Northern blotting (Fig. 2) in all except for one line (M-4) which was detected only by RT-PCR. Expression levels of the transgene mRNAs were between 3 and $12 \%$ of the total cTnT mRNA pool (corrected to GAPDH mRNA) in the cTnT-Arg ${ }^{92}$ lines and up to $15 \%$ in the cTnT-Gln ${ }^{92}$ lines (Table II). Expression levels of the endogenous cTnT mRNA, detected using a mouse cTnT-specific probe, remained unchanged among the groups.

Immunoblotting. Immunoblotting was performed using the transgene-specific antibody 2D10 which detected the presence of the $35-\mathrm{kD}$ cTnT transgene proteins in the myocardium in normal and mutant lines as shown in Fig. 3. Expression levels of the cTnT transgene proteins varied from 2 to $10 \%$ in the cTnT-Arg ${ }^{92}$ lines and from 0 (M-4) to $9 \%(\mathrm{M}-2)$ in the cTnTGln ${ }^{92}$ lines (Table II). Expression levels of the total cTnT protein pool, detected using the pan-specific monoclonal antibody

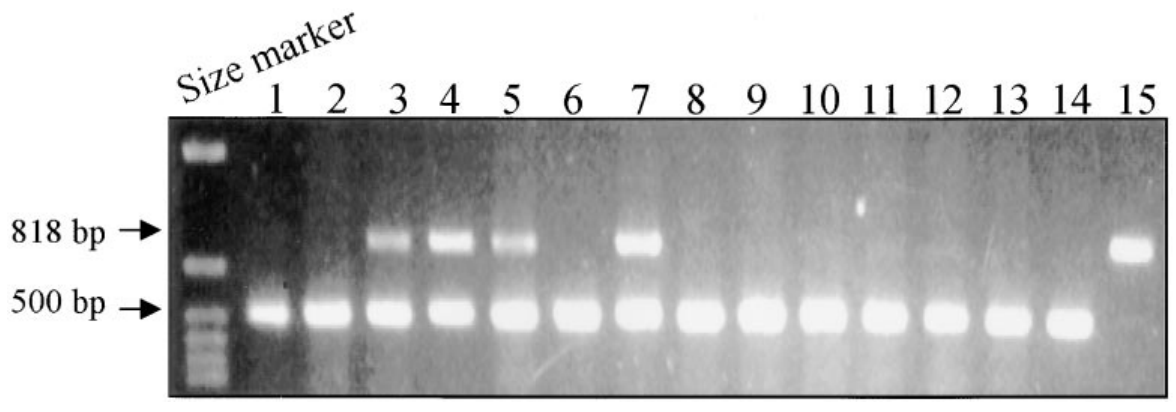

Figure 1. Identification of transgenic mice by PCR analysis. An 818-bp PCR product was amplified using transgene-specific primers. A 500-bp fragment of the mouse $\beta$-casein gene was also amplified as an internal control. The 818-bp products are present in lanes 3,4,5, and 7, thus identifying the transgenic mice. Lane 14 is a negative control (nonmanipulated mouse) and lane 15 is a positive control (transgene template). 


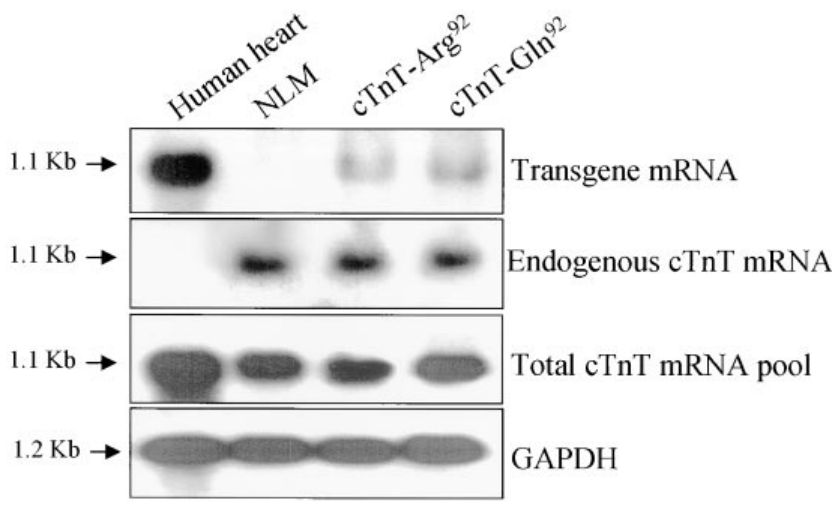

Figure 2. Northern blotting. Expression of the transgene mRNA in cTnT-Arg ${ }^{92}$ and cTnT-Gln ${ }^{92}$ lines was confirmed by Northern blotting using a 160-bp transgene-specific probe (top row). Hybridization of the radiolabeled transgene-specific probe to RNA blots showed the presence of a 1.1-kb band, size of the full-length transgene mRNA, in lanes representing human heart RNA extract (positive control), and normal (N-2) or mutant (M-2) transgenic lines but not in the lane representing a normal littermate. Expression levels of the endogenous (mouse) cTnT mRNA was determined using a 150-bp mouse cTnTspecific probe (second row). A 1.1-kb product was present in lanes representing a normal littermate, normal and mutant cTnT cDNA, whereas it was absent in the human heart mRNA extract (negative control). As shown, expression levels of the endogenous cTnT mRNAs were not significantly different among the groups. Expression of the total cTnT mRNA (endogenous plus transgene) was determined using a 950-bp pan-specific probe (third row). The 1.1-kb band was present in all lanes, representing human heart (positive control), normal and mutant transgenic mice, and a normal littermate. The last row shows expression of the GAPDH mRNA detected using a 350bp probe as an internal control for loading conditions.

JLT-12, remained unchanged and were equal to cTnT protein levels in the normal littermates.

M-mode and Doppler echocardiography. M-mode and Doppler echocardiography were performed in nine normal cTnT$\operatorname{Arg}^{92}$ (six male and three female), nine mutant cTnT-Gln ${ }^{92}$ (seven male and two female) transgenic mice, and six normal littermates (five male and one female). All mice were $\sim 3$ mo old and the mean ages were not significantly different among the groups. The intraobserver variability of the peak aortic outflow and $\mathrm{E}$ and $\mathrm{A}$ velocities were measured for 20 mice in random sequence on two different days and were 3.3, 2.7, and $3.5 \%$ (differences between two measurements/mean of measurements $\times 100)$, respectively. Representative echocardio-

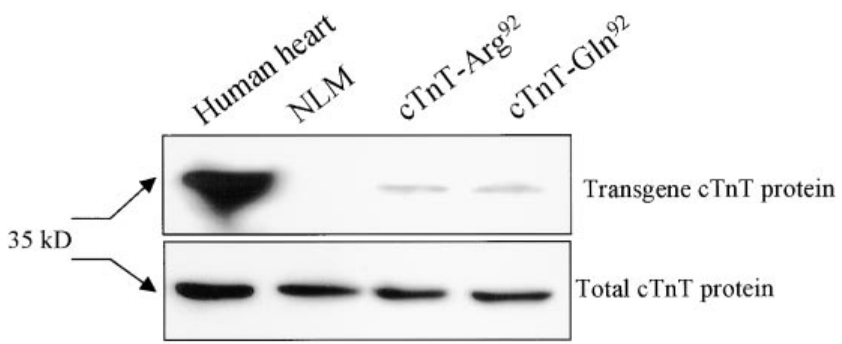

Figure 3. Immunoblotting. The top shows expression of the transgenes into proteins detected using the monoclonal antibody 2D10. As shown, a 35-kD band was present in lanes representing the human heart protein extract (positive control), normal (N-2), and mutant (M-2) cTnT transgenic mice. However, no specific band was detected in the normal littermate. The bottom shows expression of the total cTnT (transgene plus endogenous) detected using the pan-specific antibody JLT-12. As shown, a 35-kD band was present in lanes representing the human heart protein extract, normal littermate, and normal and mutant transgenic mice.

grams are shown in Fig. 4. The mean ST, PWT, LVESD, LVEDD, and FS were not significantly different between normal and mutant cTnT lines or from the corresponding values in the normal littermates (Table I). There were no significant differences in the aortic outflow velocities and the mitral valve inflow E velocities (Table II). However, as shown in Fig. 4 and Table I, atrial (A) component of mitral valve inflow velocities was significantly increased in the mutant cTnT transgenic mice as compared with normal cTnT transgenic mice or the normal littermates $(30 \pm 7$ vs. $14 \pm 6$ vs. $15 \pm 4 \mathrm{~cm} / \mathrm{s}$, respectively, $P<$ $0.0001)$. Moreover, the E/A ratio, a commonly used index of left ventricular diastolic function, was reduced by $\sim 50 \%$ in the mutant cTnT transgenic mice (Table II) indicating diastolic dysfunction $(P<0.0001)$.

Histology. Cardiac myocyte disarray and increased interstitial collagen content were present in the cTnT-Gln ${ }^{92}$ transgenic mice, but not in the normal (cTnT-Arg ${ }^{92}$ ) mice as shown in Fig. 5. The proportion of myocardium showing disarray was measured in 10 thin myocardial sections per mouse and in a total of 6 mice per line and was expressed as a percentage of the total cross-sectional area. Myocyte disarray occupied $<1 \%$ of the total cross-sectional area of the myocardial sections in the normal cTnT transgenic mice (Table II) and normal littermates and was restricted to the junction of the two ventricles at the interventricular septum. However, in the mutant cTnT$\mathrm{Gln}^{92}$ mice, the extent of cardiac myocyte disarray varied from $<1 \%$ (line M-4) to $15 \%$ (line M-2) of the total myocardial sec-

Table II. Expression Levels of Transgenes and the Extent of Cardiac Myocyte Disarray

\begin{tabular}{|c|c|c|c|c|c|c|c|c|}
\hline & \multicolumn{3}{|c|}{ cTnT-Arg ${ }^{92}$ lines } & \multicolumn{5}{|c|}{ cTnT-Gln ${ }^{92}$ lines } \\
\hline & $\mathrm{N}-1$ & $\mathrm{~N}-2$ & $\mathrm{~N}-3$ & M-1 & $\mathrm{M}-2$ & $\mathrm{M}-3$ & M-4 & M-5 \\
\hline Copy number & 6 & 22 & 4 & 15 & 11 & 18 & 4 & 13 \\
\hline Tg-cTnT mRNA ( $\%$ of total cTnT mRNA) & $5 \%$ & $12 \%$ & $3 \%$ & $7 \%$ & $15 \%$ & $8 \%$ & PCR* & $5 \%$ \\
\hline Tg-cTnT protein ( $\%$ of total cTnT mRNA) & $2 \%$ & $10 \%$ & $5 \%$ & $4 \%$ & $9 \%$ & $5 \%$ & ND & $2 \%$ \\
\hline Disarray (\% of myocardium) & $<1 \%$ & ND & ND & $8 \%$ & $15 \%$ & $10 \%$ & $<1 \%$ & $5 \%$ \\
\hline
\end{tabular}

*Expression of the transgene into mRNA was detected by RT-PCR using transgene-specific primers (RT primer: $5^{\prime}$ ttactggtgtggagtgggtgtg3'; PCR forward primer: 5'ttgggggttacatccagaagcag3'; and PCR reverse primer: 5'agatctttggtgaaggaggccag3'). The size of the amplified fragment was 491 bp. $T g-c T n T$, cTnT; $N D$, not detected. 
NLM
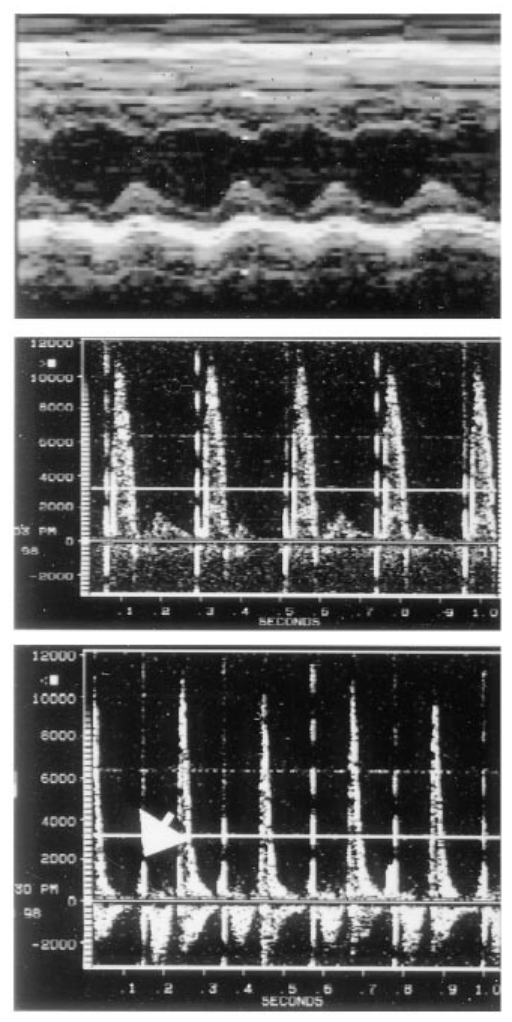

cTnT-Arg 92
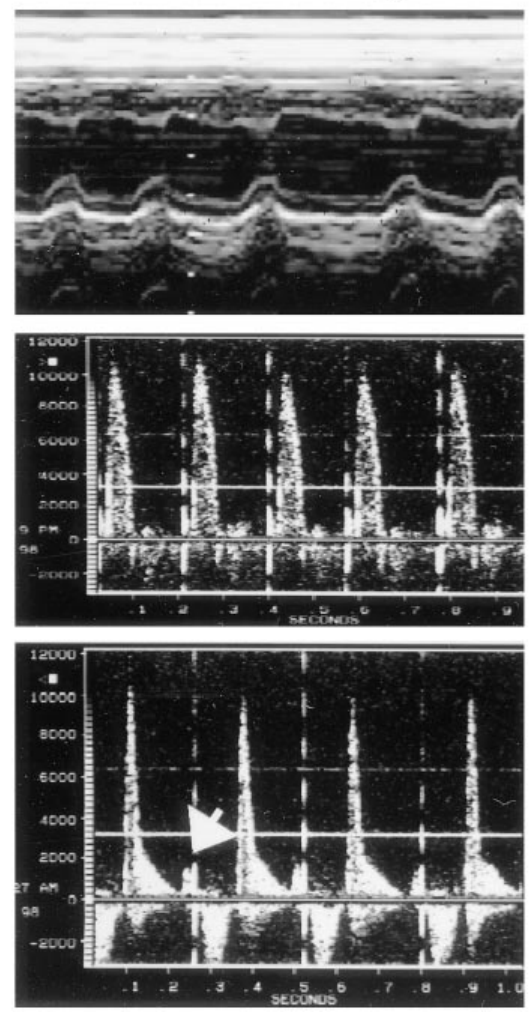

$\mathrm{cTnT}-\mathrm{G} \ln { }^{92}$
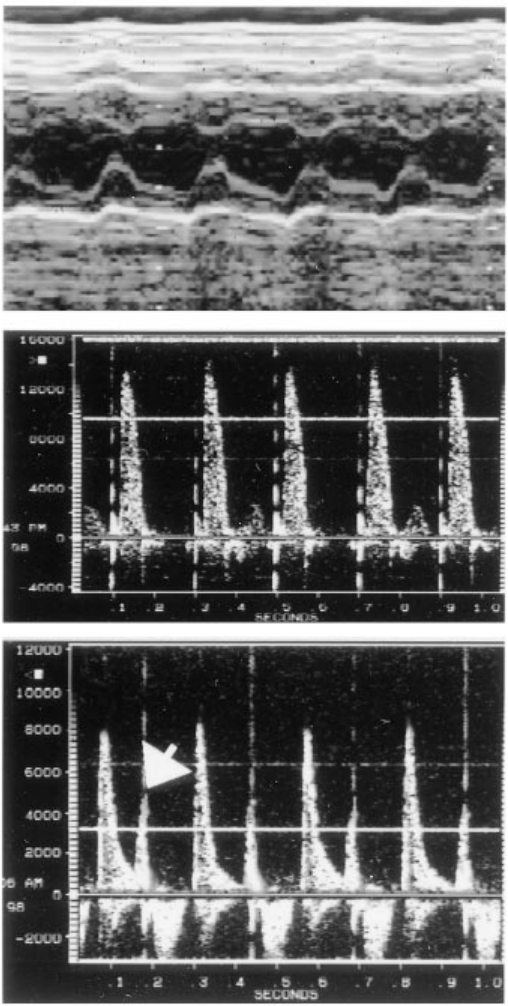

Figure 4. M-mode and Doppler echocardiography. The top row shows M-mode echocardiograms, the middle row shows aortic outflow tract velocities, and the lower row shows mitral valve inflow velocities. As shown, interventricular ST, PWT, LVESD, and LVEDD were not significantly different among the groups. Peak aortic velocities were also similar (middle row). However, mitral inflow velocities were significantly altered in the mutant cTnT transgenic mice (lines M-2 and M-3) as compared with the normal cTnT transgenic mice (lines N-2 and N-3) or the normal littermates. E velocities were higher and A velocities were minimal in the normal cTnT transgenic mice and normal littermates resulting in $\mathrm{E} / \mathrm{A}$ ratio between 5 and 10. In contrast, $\mathrm{E}$ velocities were slightly lower and A velocities were significantly increased resulting in a mean E/A ratio of 2.2 in the mutant transgenic mice which indicates significant diastolic dysfunction.

tion and was distributed throughout the myocardium without a preference for the interventricular septum (Table II). Myocyte disarray was most extensive in the mice (M-2 line) with the highest level of expression of the mutant cTnT-Gln ${ }^{92}$ protein (Fig. 5). Interstitial collagen content was quantified in 30 myocardial sections in each group and was increased by twofold in the mutant cTnT-Gln ${ }^{92}$ transgenic mice compared with the normal cTnT-Arg ${ }^{92}$ mice or normal littermates $(P<0.01)$.

\section{Discussion}

We have produced transgenic mice expressing low levels of normal (cTnT- $\mathrm{Arg}^{92}$ ) or mutant (cTnT-Gln ${ }^{92}$ ) cTnT proteins, the latter known to cause HCM in humans (9). Levels of expression of the mutant cTnT-G $\ln ^{92}$ in the heart, detected using a transgene-specific probes, were $<10 \%$ of the endogenous cTnT levels. Despite the relatively low levels of expression, the mutant cTnT-Gln ${ }^{92}$ induced cardiac myocyte disarray, increased myocardial interstitial collagen content, and diastolic dysfunction in transgenic mice. The observed phenotypes are virtually identical to HCM phenotypes in humans (2). We conclude that cTnT-Gln ${ }^{92}$ exerted a dominant-negative effect on cardiac myocyte structure and function in vivo. Thus, the re- sults of these studies support the proposed "poison-peptide hypothesis" in the pathogenesis of $\operatorname{HCM}(4,9,18-22)$.

Despite the presence of significant cardiac myocyte disarray, diastolic dysfunction, and increased interstitial collagen content, three common features of human HCM, cardiac hypertrophy was absent in the cTnT-Gln ${ }^{92}$ transgenic mice. Many factors may account for the absence of cardiac hypertrophy in cTnT-Gln ${ }^{92}$ transgenic mice. Clearly, indices of ST, PWT, and heart weight/body weight ratio do not directly measure the size of cardiac myocytes. Thus, despite absence of cardiac hypertrophy on echocardiograms and absence of enlarged cardiac myocytes on qualitative histological examination, these assessments do not exclude minute yet significant increase in the size of cardiac myocytes. Analysis of cardiac myocyte size requires a more quantitative technique. It is also of note that the lack of cardiac hypertrophy in the cTnT-Gln ${ }^{92}$ transgenic mice is in keeping with the phenotype of mild or no hypertrophy observed in human HCM due to this mutation $(9,14)$. In addition, the development of cardiac hypertrophy may depend on the dose of the mutant sarcomeric protein. Expression levels of the cTnT-GIn ${ }^{92}$ were $<10 \%$ in all transgenic lines. Thus, the impact of higher levels of expression of the cTnT-Gln ${ }^{92}$ on cardiac hypertrophy remains unknown. Furthermore, familial cases of HCM exhibiting severe myocyte disarray but no car- 


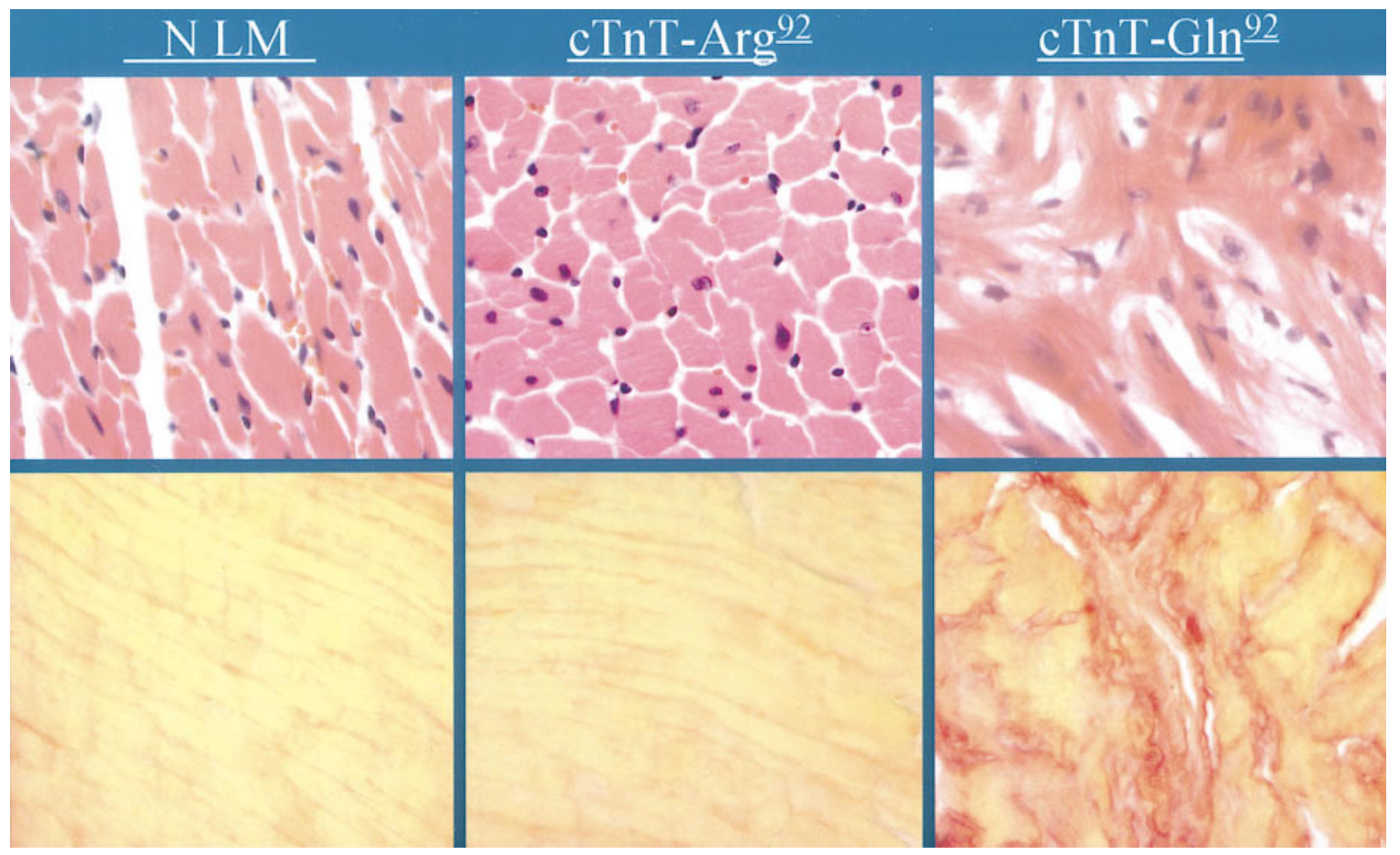

Figure 5. Histology. The top and bottom rows show hematoxylin and eosin and picrosirius red staining, respectively. The structure of cardiac myocytes was intact in the normal littermate (right), and the transgenic cTnT-Arg ${ }^{92}$ mice (middle, picture shown for line $\mathrm{N}-2$ ). However, as shown, severe cardiac myocyte disarray was present in the transgenic cTnT-Gln ${ }^{92}$ mice (left, picture shown for line M-2). Interstitial collagen content was minimal in the normal littermates as well as in the transgenic cTnT-Arg ${ }^{92}$ mice. In contrast, interstitial collagen content was increased significantly (twofold, $P<0.01$ ) in the cTnT-Gln ${ }^{92}$ transgenic mice (figure from line $\mathrm{M}-2$, lower right corner).

diac hypertrophy have been described also (37). These clinical observations are in accord with our findings in the transgenic mice and suggest that myocyte disarray may precede and occur independently of the development of cardiac hypertrophy. Moreover, expression of hypertrophy in HCM is determined not only by the individual responsible gene and mutation but also by the modifier genes and the nongenetic factors $(15,38)$. It is also intriguing that interstitial collagen content was increased significantly in the cTnT-Gln ${ }^{92}$ transgenic mice, a phenotype common in human HCM (2). The mechanism leading to an increased interstitial collagen content in the myocardium remains to be explored. We propose that impaired cardiac myocyte function, as shown previously after expression of mutant cTnT protein in cultured cells $(18,19)$, leads to synthesis of a number of autocrine and paracrine factors such as angiotensin II that not only mediate the increased collagen synthesis but also cardiac hypertrophy. Therefore, these results further support the notion that altered cardiac myocyte function and disarray are the primary abnormalities in HCM and hypertrophy is a compensatory process that is regulated by a number of genetic and nongenetic factors.

The results of this study further corroborate the results of the previous in vitro and in vivo studies and support the dominant-negative impact of the mutant sarcomeric proteins on cardiac structure and function (18-22). Vikstrom et al. produced transgenic mice expressing mutant $\alpha$-MyHC $\left(-\mathrm{Gln}^{403}\right)$ and showed that a low level of expression of the mutant protein was sufficient to induce cardiac myocyte disarray (21). The expression levels of the mutant $\alpha$-MyHC-Gln ${ }^{403}$ protein were $\sim 0.6-12 \%$ of the endogenous $\alpha$-MyHC protein (21). Al- though the $\alpha-\mathrm{MyHC}$ is not a responsible gene for human $\mathrm{HCM}$ and is expressed only at low levels in the myocardium of large adult mammals including humans, nevertheless, it is the predominant myosin in the mouse heart (ventricle) as is the $\beta$-MyHC in the human heart (39). Furthermore, GeisterferLowrance et al. introduced a missense mutation ( $\mathrm{Arg}^{403} \mathrm{Gln}$ ) into mouse cardiac $\alpha$-MyHC gene through gene targeting and described cardiac myocyte disarray and interstitial fibrosis, a phenotype similar to HCM in humans (22). Preliminary results of expression of a truncated cTnT protein in mice also support a dominant-negative influence on cardiac myocyte structure in transgenic mice (40). Therefore, the results of previous in vivo studies of the mutant $\alpha-\mathrm{MyHC}-\mathrm{Gln}^{403}$ and the present studies of mutant cTnT-Gln ${ }^{92}$ are concordant and show a dominantnegative effect of the mutant sarcomeric proteins on cardiac myocytes structure and function in transgenic mice.

Given the diversity of genes and mutations responsible for $\mathrm{HCM}$, the mechanism described for a particular mutation in a transgenic model may not apply to other mutations, in particular deletion mutations. Indeed, identification of deletion mutations in the $\beta$-MyHC or the MyBP-C genes has put forth the "null-allele" hypothesis $(26,41)$. Certain deletion mutations, responsible for human $\mathrm{HCM}$, code for truncated proteins that, even if synthesized, are not expected to be incorporated into myofibrils $(26,41)$. Further credence to the null-allele hypothesis is provided by the results of recent gene targeting experiments, whereby ablation of one copy of the murine $\alpha$-MyHC gene led to altered sarcomere structure and myocardial function (42). The null-allele, also known as the "haploinsufficiency" hypothesis, proposes that altered stoichiometry of the 
components of the sarcomeric proteins impairs sarcomerogenesis and leads to myofibrillar disarray $(41,42)$. The impact of altered stoichiometry of the sarcomeric proteins on sarcomere structure has also been observed in Drosophila melanogaster, whereby null mutations in actin or MyHC genes resulted in myofibrillar defects (43). Thus, deletion mutations that lead to null allele could induce HCM through haplodeficiency.

In summary, the results of these experiments show that low levels of expression of the mutant cTnT-G $\ln ^{92}$ in transgenic mice lead to cardiac myocyte disarray, increased interstitial collagen content, and diastolic dysfunction, phenotypes similar to those commonly observed in human HCM. Thus, the cTnTGln ${ }^{92}$ protein which is known to cause HCM in humans exerts a dominant-negative effect on cardiac structure and function.

\section{Acknowledgments}

This work was supported in part by an Established Investigator Award (9640133N) from the American Heart Association, and Specialized Centers of Research (P50-HL42267-01 and P01-HL42550-08) grants from National Heart, Lung, and Blood Institute.

\section{References}

1. Marian, A.J., and R. Roberts. 1995. Recent advances in the molecular genetics of hypertrophic cardiomyopathy. Circulation. 92:1336-1347.

2. Maron, B.J., and W.C. Roberts. 1978. Quantitative analysis of cardiac muscle cell disorganization in the ventricular septum of patients with hypertrophic cardiomyopathy. Circulation. 59:689-706.

3. Thierfelder, L., H. Watkins, C. MacRae, R. Lamas, W. McKenna, H.-P. Vosberg, J.G. Seidman, and C.E. Seidman. 1994. $\alpha$-Tropomyosin and cardiac troponin $\mathrm{T}$ mutations cause familial hypertrophic cardiomyopathy: a disease of the sarcomere. Cell. 77:701-712.

4. Geisterfer-Lowrance, A.A., S. Kass, G. Tanigawa, H.-P. Vosberg, W. McKenna, C.E. Seidman, and J.G. Seidman. 1990. A molecular basis for familial hypertrophic cardiomyopathy: a $\beta$-cardiac myosin heavy chain gene missense mutation. Cell. 62:999-1006.

5. Watkins, H., D. Conner, L. Thierfelder, J.A. Jarcho, C. MacRae, W.J. McKenna, B.J. Maron, J.G. Seidman, and C.E. Seidman. 1995. Mutations in the cardiac myosin binding protein-C gene on chromosome 11 cause familial hypertrophic cardiomyopathy. Nat. Genet. 11:434-437.

6. Bonne, G., L. Carrier, J. Bercovici, C. Cruaud, P. Richard, B. Hainque, M. Gautel, S. Labeit, M. James, J. Beckmann, et al. 1995. Cardiac myosin binding protein-C gene splice acceptor site mutation is associated with familial hypertrophic cardiomyopathy. Nat. Genet. 11:438-440.

7. Poetter, K., H. Jiang, S. Hassanzadeh, S. Master, A. Chang, M.C. Dalakas, I. Rayment, J.R. Sellers, L. Fananapazir, and N.D. Epstein. 1996. Mutations in either the essential or regulatory light chains of myosin are associated with a rare myopathy in human heart and skeletal muscle. Nat. Genet. 13:63-69.

8. Kimura, A., H. Harada, J.-E. Park, H. Nishi, M. Satoh, M. Takahashi, S. Hiroi, T. Sasaoka, N. Ohbuchi, T. Nakamura, et al. 1997. Mutations in the cardiac troponin I gene associated with hypertrophic cardiomyopathy. Nat. Genet. 16:379-382.

9. Watkins, H., W.J. McKenna, L. Thierfelder, J. Suk, R. Anan, A. O'Donoghue, P. Spirito, A. Matsumori, C.E. Moravec, J.G. Seidman, and C.E. Seidman. 1995. Mutations in the genes for cardiac troponin T and $\alpha$-tropomyosin in hypertrophic cardiomyopathy. N. Engl. J. Med. 332:1058-1064.

10. Nimura, H., L.L. Bachinski, S. Sangwatanaroj, H. Watkins, A.E. Chudley, W. McKenna, A. Kristinsson, R. Roberts, M. Sole, B.J. Maron, et al. 1998. Mutations in the gene for cardiac myosin binding protein $\mathrm{C}$ and late-onset familial hypertrophic cardiomyopathy. N. Engl. J. Med. 338:1248-1257.

11. Fananapazir, L., and N.D. Epstein. 1994. Genotype-phenotype correlations in hypertrophic cardiomyopathy: insights provided by comparisons of kindreds with distinct and identical $\beta$-myosin heavy chain gene mutations. Circulation. 89:22-32.

12. Marian, A.J., A. Mares, D. Kelley, Q.-T. Yu, R. Hill, M.B. Perryman, R.W. Young, and R. Roberts. 1995. Sudden death in hypertrophic cardiomyopathy: genotype-phenotype correlation of beta myosin heavy chain mutations. Eur. Heart J. 16:368-376.

13. Abchee, A., and A.J. Marian. 1997. Prognostic significance of $\beta$-myosin heavy chain mutations is reflective of their hypertrophic expressivity in patients with hypertrophic cardiomyopathy. J. Invest. Med. 45:191-196.

14. Forissier, J.-F., L. Carrier, H. Farza, G. Bonne, J. Bercovici, P. Richard, B. Hainque, P.J. Townsend, M.H. Yacoub, S. Faure, et al. 1996. Codon 102 of the cardiac troponin $\mathrm{T}$ gene is a putative hot spot for mutations in familial hypertrophic cardiomyopathy. Circulation. 94:3066-3073.

15. Lechin, M., M. Quinones, A. Omran, R. Hill, Q.-T. Yu, H. Rakowski, D. Wigle, C.C. Liew, M. Sole, R. Roberts, and A.J. Marian. 1995. Angiotensin 1 converting enzyme genotypes influence the phenotypic expression of hypertrophic cardiomyopathy. Circulation. 92:1808-1812.

16. Sata, M., and M. Ikebe. 1996. Functional analysis of the mutations in the human cardiac $\beta$-myosin that are responsible for familial hypertrophic cardiomyopathy. Implication for the clinical outcome. J. Clin. Invest. 98:28662873.

17. Lankford, E.B., N.D. Epstein, L. Fananapazir, and H.L. Sweeney. 1995. Abnormal contractile properties of muscle fibers expressing $\beta$-myosin heavy chain gene mutations in patients with hypertrophic cardiomyopathy. J. Clin. Invest. 95:1409-1414.

18. Watkins, H., C.E. Seidman, J.G. Seidman, H.S. Feng, and H.L. Sweeney. 1996. Expression and functional assessment of a truncated cardiac troponin $\mathrm{T}$ that causes hypertrophic cardiomyopathy. Evidence for a dominant negative action. J. Clin. Invest. 98:2456-2461.

19. Marian, A.J., G. Zhao, Y. Seta, R. Roberts, and Q.-T. Yu. 1997. Expression of a mutant $\left(\mathrm{Arg}^{92} \mathrm{Gln}\right)$ human cardiac troponin $\mathrm{T}$, known to cause hypertrophic cardiomyopathy, impairs adult cardiac myocytes contractility. Circ. Res. 81:76-85.

20. Marian, A.J., Q.-T. Yu, D. Mann, F. Graham, and R. Roberts. 1995. Expression of the mutation causing hypertrophic cardiomyopathy disrupts sarcomere assembly in adult feline cardiac myocytes. Circ. Res. 77:98-106.

21. Vikstrom, K.L., S.M. Factor, and L.A. Leinwand. 1996. Mice expressing mutant myosin heavy chains are a model for familial hypertrophic cardiomyopathy. Mol. Med. 2:556-567.

22. Geisterfer-Lowrance, A.A.T., M. Christe, D.A. Conner, J.S. Ingwall, F.J. Schoen, C.E. Seidman, and J.G. Seidman. 1996. A mouse model for familial hypertrophic cardiomyopathy. Science. 272:731-734.

23. Nelson, R.M., and G.L. Long. 1989. A general method of site-specific mutagenesis using a modification of the Thermus aquaticus polymerase chain reaction. Anal. Biochem. 180:147-151.

24. Wang, G., H.-I. Yeh, and J.J.-C. Lin. 1994. Characterization of cis-regulating elements and trans-activating factors of the rat cardiac troponin $\mathrm{T}$ gene. J. Biol. Chem. 269:30595-30603.

25. DeMayo, F.J., and D.W. Bullock. 1987. Microinjection and transfer of mouse embryos. In Laboratory Methods: Manual for Hormone Action and Molecular Endocrinology. W.T. Schraderr and B.W. O’Malley, editors. Houston Biological Association, Inc. Houston, TX.

26. Marian, A.J., Q.T. Yu, A. Mares, Jr., R. Hill, R. Roberts, and M.B. Perryman. 1992. Detection of a new mutation in the beta myosin heavy chain gene in an individual with hypertrophic cardiomyopathy. J. Clin. Invest. 90:21562165

27. Feinberg, A.P., and B. Vogelstein. 1983. A technique for radiolabelling DNA restriction nuclease fragments to high specific activity. Anal. Biochem. 132:6-13.

28. Chomczynski, P., and N. Sacchi. 1987. Single-step method of RNA isolation by acid guanidinium thiocyanate-phenol-chloroform extraction. Anal. Biochem. 162:156-169.

29. Townsend, P.J., H. Farza, C. MacGeon, N.K. Spurr, R. Wade, R. Gahlmann, M.H. Yacoub, and P.J.R. Barton. 1994. Human cardiac troponin T: identification of fetal isoforms and assignment of the TNNT2 locus to chromosome 1q. Genomics. 21:311-316.

30. Jin, J.-P., J. Wang, and J. Zhang. 1996. Expression of mouse cardiac troponin $\mathrm{T}$ isoforms: characterization of a large number of independent clones. Gene. 168:217-221.

31. Deitiker, P.R., and H.F. Epstein. 1993. Thick filament substructures in Caenorhabditis elegans: evidence for two population of paramyosin. J. Cell Biol. 123:303-311.

32. Hartley, C.J., L.H. Michael, and M.L. Entman. 1995. Noninvasive measurement of ascending aortic blood velocity in mice. Am. J. Physiol. 268:H499H505.

33. Taffet, G.E., C.J. Hartley, X. Wen, T. Pham, L.H. Michael, and M.L. Entman. 1996. Noninvasive indexes of cardiac systolic and diastolic function in hyperthyroid and senescent mouse. Am. J. Physiol. 270:H2204-H2209.

34. Taffet, G.E., T.T. Pham, and C.J. Hartley. 1997. The age-associated alterations in late diastolic function in mice are improved by caloric restriction. $J$. Gerontol. 52A:B285-B290.

35. Michael, L.H., M.L. Entman, C.J. Hartley, K.A. Youker, J. Zhu, S.R. Hall, H.K. Hawkins, K. Berens, and C.M. Ballantyne. 1995. Myocardial ischemia and reperfusion: a murine model. Am. J. Physiol. 269:H2147-H2154.

36. Lopez-De Leon, A., and M. Rojkind. 1985. A simple micromethod for collagen and total protein determination in formalin-fixed paraffin-embedded sections. J. Histochem. Cytochem. 33:737-743.

37. McKenna, W.J., J.T. Stewart, P. Nihoyannopoulos, F. McGinty, and M.J. Davies. 1990. Hypertrophic cardiomyopathy without hypertrophy: two families with myocardial disarray in the absence of increased myocardial mass. Br. Heart J. 63:287-290.

38. Brugada, R., W. Kelsey, M. Lechin, G. Zhao, Q.-T. Yu, W. Zoghbi, M. Quinones, E. Elstein, A. Omran, H. Rakowski, et al. 1997. Role of candidate 
modifier genes on the phenotypic expression of hypertrophy in patients with hypertrophic cardiomyopathy. J. Invest. Med. 45:542-551.

39. Swynghedauw, B. 1986. Development and functional adaptation of contractile proteins in cardiac and skeletal muscles. Physiol. Rev. 66:710-771.

40. Tardiff, J., S.M. Factor, T. Hewett, J. Robbins, and L.A. Leinwand. 1997. Expression of a mutant cTnT molecule implicated in familial hypertrophic cardiomyopathy results in widespread ventricular remodelling in transgenic mice. Circulation. 96:I-10. (Abstr.)

41. Rottbauer, W., M. Gautel, J. Zehelein, S. Labett, W.M. Franz, C. Fisher, B. Vollrath, G. Mall, R. Dietz, W. Kubler, and H.A. Katus. 1997. Novel splice donor site mutation in the cardiac myosin-binding protein- $\mathrm{C}$ gene in familial hypertrophic cardiomyopathy. Characterization of cardiac transcript and protein. J. Clin. Invest. 100:475-482.

42. Jones, W.K., I.L. Grupp, T. Doetschman, G. Grupp, H. Osinska, T.E. Hewett, G. Boivin, J. Gulick, W.A. Ng, and J. Robbins. 1996. Ablation of the murine $\alpha$ myosin heavy chain gene leads to dosage effects and functional deficits in the heart. J. Clin. Invest. 98:1906-1917.

43. Beal, C.J., M.A. Sepanski, and E.A. Fyrberg. 1989. Genetic dissection of Drosophila myofibril formation: effects of actin and myosin heavy chain null alleles. Genes Dev. 3:131-140. 